\title{
Adrenomedullin-RAMP2 System in Vascular Endothelial Cells
}

\author{
Teruhide Koyama $^{1,2}$, Takayuki Sakurai ${ }^{2}$, Akiko Kamiyoshi², Yuka Ichikawa-Shindo², Hisaka Kawate ${ }^{2}$ and \\ Takayuki Shindo²
}

\footnotetext{
${ }^{1}$ Department of Epidemiology for Community Health and Medicine, Kyoto Prefectural University of Medicine Graduate School of Medical Science, Kyoto, Japan

${ }^{2}$ Department of Cardiovascular Research, Shinshu University Graduate School of Medicine, Nagano, Japan
}

\begin{abstract}
Vascular endothelial cells play key roles in maintaining vascular and organ homeostasis. Adrenomedullin (AM), originally identified as a vasodilating peptide, is now recognized to be a pleiotropic molecule involved in both circulatory homeostasis and the pathogenesis of cardiovascular diseases. We have reported that knockout mice deficient in AM or receptor activity-modifying protein 2 (RAMP2), an AM-receptor accessory protein, show vascular endothelial cell deformities that are embryonically lethal. To directly clarify the pathophysiological functions of the vascular AM-RAMP2 system, we generated vascular endothelial cell-specific RAMP2 knockout mice. Using these mice, we found that the AM-RAMP2 system is a key determinant of vascular integrity and homeostasis from prenatal stages through adulthood. This review highlights the functions of AM-RAMP2 in vascular endothelial cells.
\end{abstract}

JAtheroscler Thromb, 2015; 22: 647-653.

Key words: Adrenomedullin (AM), Receptor activity-modifying protein (RAMP), Vascular endothelial cell, Vascular integrity, Homeostasis

\section{Introduction}

Atherosclerosis is the most frequently occurring cause of chronic organ dysfunction and shortens the healthy life span of a large numbers of individuals. Various acquired and congenital factors can accelerate the progression of organ dysfunction; however, the primary cause is still a matter of considerable debate. Generally, organ dysfunction begins slowly; however, it is progressive and intractable in its chronic phase ${ }^{1,2)}$. From a functional viewpoint, chronic organ dysfunction is caused by the dysregulation of physiological homeostasis and its repair processes. The vascular system, in particular, plays a crucial role in organ homeostasis because it is essential for organ and tissue construction, supplies oxygen and nutrients, and mobi-

Address for correspondence: Takayuki Shindo, Department of Cardiovascular Research, Shinshu University Graduate School of Medicine, Asahi 3-1-1, Matsumoto, Nagano, 390-8621, Japan

E-mail: tshindo@shinshu-u.ac.jp

Received: January 28, 2015

Accepted for publication: May 18, 2015 lizes inflammatory cells to regions of injury ${ }^{3,4}$. Ischemic diseases are caused by reductions in the blood supply due to atherosclerosis or thrombosis. On the other hand, while regeneration of the vasculature is a hoped-for treatment of ischemic diseases, dysregulated angiogenesis can exacerbate malignant tumors, diabetic retinopathy, and chronic inflammatory diseases. It was also recently demonstrated that vascular senescence and failure are closely associated with heart disease, cerebrovascular disease, cancer, and chronic inflammation $^{5}$. In addition, the vascular endothelial system can be considered the largest system in the body, given its length and area, and the vascular endothelial cells, through their active secretion of bioactive molecules, play central roles in vascular homeostasis ${ }^{6-8)}$. Revealing the mechanisms underlying the functional integrity of the vascular endothelial system could serve as the basis for novel approaches to therapy.

Adrenomedullin (AM) is a bioactive peptide first identified in human pheochromocytoma ${ }^{9)}$. Although $\mathrm{AM}$ is now known to be secreted from various organs and tissues, it is mainly produced by vascular endothelial cells and serves numerous physiological functions. 
AM initially attracted attention as a vasoactive peptide that induced vasodilation and lowered blood pressure $^{9)}$. In subsequent studies, however, AM was shown to also have anti-inflammatory, anti-apoptotic, and anti-oxidative properties, to name a few ${ }^{10-12)}$. In addition, plasma AM levels are elevated in patients with hypertension, congestive heart failure, or myocardial infarction ${ }^{11,13)}$, suggesting that $\mathrm{AM}$ is involved in these diseases in some way.

We previously reported that AM knockout (AM-/-) mice die in utero at mid-gestation because of abnormalities in their vasculature structure ${ }^{14)}$. From that result, it was apparent that $\mathrm{AM}$ is indispensable for proper vascular development. Heterozygous AM knockout $(\mathrm{AM}+/-)$ mice grow to adulthood and exhibit no obvious abnormality at first glance. However, upon injury to the cardiovascular system, subsequent cardiac hypertrophy and fibrosis, renal failure, and arteriosclerosis are all worse in $\mathrm{AM}+/$ - mice than control mice. By contrast, we also observed that AM exerts organprotective and anti-arteriosclerotic effects, and that blood vessel-specific AM transgenic mice are resistant to organ damage and arteriosclerosis ${ }^{15-17)}$. On the basis of these observations, AM is now thought of as a pleiotropic bioactive molecule, and its clinical application is much anticipated ${ }^{12,18)}$.

Calcitonin gene related-peptide (CGRP) is in the same peptide family as AM and shares with AM a seven transmembrane domain $G$ protein-coupled receptor, called calcitonin receptor-like receptor $(\mathrm{CLR})^{19,20)}$. The specificity of CLR for AM and CGRP is thought to be regulated by receptor activity-modifying proteins (RAMPs), which are membrane proteins having a single membrane-spanning domain. Three RAMP subtypes (RAMP1, 2, and 3) have been identified. By interacting with RAMP1, CLR acquires high affinity for CGRP; by interacting with RAMP2 or RAMP3, CLR acquires high affinity for AM.

Despite its potential for therapeutic application, use of AM as a therapeutic drug is limited by its short half-life in the blood stream. However, we noted that the expression of RAMP2 was particularly high in vascular endothelial cells in embryonic AM-/- mice just before they die. This prompted us to speculate that RAMP2 is the primary determinant of AM functionality in blood vessels. Consistent with that idea, we previously observed that homozygous RAMP2 knockout (RAMP2-/-) mice die mid-gestation because of vascular abnormalities with systemic edema and bleeding, just as $\mathrm{AM}-/$ - mice do ${ }^{21)}$. Moreover, another group reported the effect of RAMP2 overexpression using transgenic mice, which overexpress RAMP2 in their vascular smooth muscle cells. These mice showed ele- vated vasodilatory action against $\mathrm{AM}$ administration ${ }^{22)}$. On the basis of these findings, we have worked to clarify the physiological functions of the AM-RAMP2 system in the vasculature by generating and utilizing a series of genetically engineered mice. In this review, we focus on the AM-RAMP2 system of vascular endothelial cells.

\section{Functional Biology of AM in Endothelial Cells}

AM is a member of the calcitonin (CT) peptide superfamily, which includes CT, CGRP, amylin (AMY), and intermedin ${ }^{11)}$. AM is secreted in a wide array of organs and tissues and is involved in a variety of biological functions ${ }^{12,23,24)}$, including exertion of protective effects against cardiovascular damage, possibly through inhibition of oxidative stress. Plasma AM levels are increased in conditions such as essential hypertension, renal failure, and congestive heart failure, and the magnitude of the elevation is in proportion to the severity of the disease ${ }^{11,25,26}$. The role of AM in endothelial cell growth and survival has also been reported $^{12,27)}$. AM upregulates the expression of both vascular endothelial growth factor (VEGF) and endothelial nitric oxide synthase (eNOS) ${ }^{16,28)}$, and it induces phosphorylation/activation of Akt and extracellular signal-regulated kinase (ERK)1/2. It also induces tube formation in human umbilical vein endothelial cells (HUVECs) an effect inhibited by pretreatment with a phosphoinositide 3-kinase (PI3K) inhibitor or a ERK1/2 inhibitor, and it exerts angiogenic effects through the activation of Akt, MAPK, and focal adhesion kinase in endothelial cells ${ }^{12,29)}$.

$\mathrm{AM}$ is known to regulate vascular permeability in vitro and in vivo ${ }^{21,30)}$, in part by preventing endothelial contraction and intercellular gap formation. Molecules that increase intracellular cAMP within endothelial cells strengthen barrier function and reduce endothelial permeability ${ }^{30,31)}$. AM exerts its effects by increasing the levels of intracellular cAMP via its receptors ${ }^{19,32)}$. In addition, small GTPases, particularly Rac1 and RhoA, play crucial roles in the regulation of endothelial cell barrier function by regulating the formation of cortical actin and stress fibers, respectively ${ }^{31)}$. Elevation of cAMP leads to Rac1 activation, which in turn strengthens endothelial barrier function by enhancing cortical actin ring formation ${ }^{33)}$. AMstimulated endothelial cells exhibit cortical actin formation, which disappears upon treatment with a Rac1 inhibitor $^{34)}$. 
A

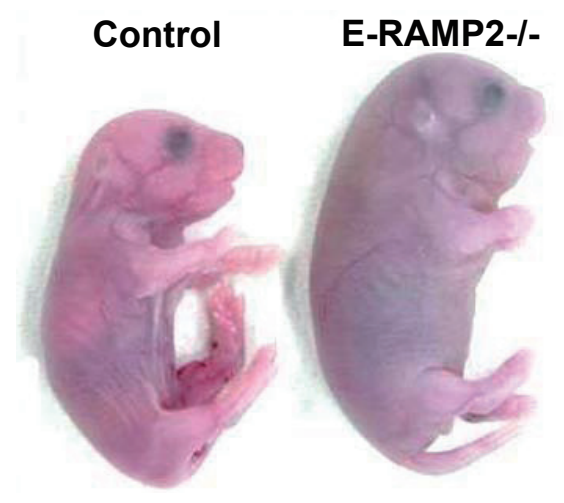

B

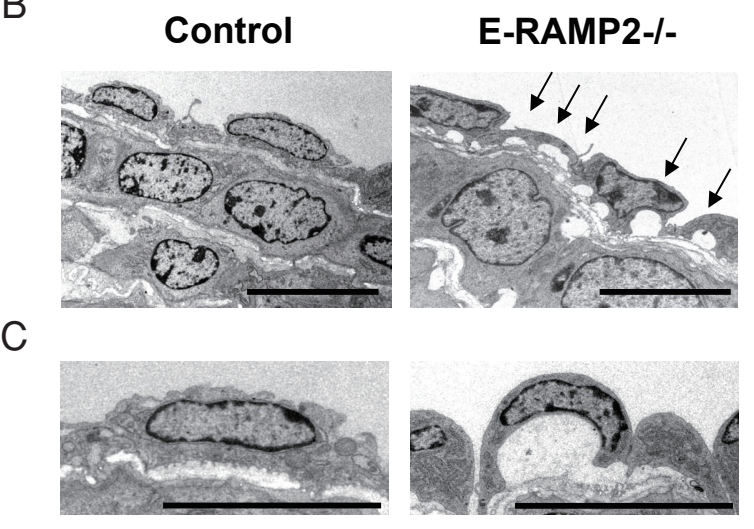

Fig. 1. E-RAMP2-/- mice show high perinatal mortality with systemic edema and the severe deformation of endothelial cells (cited from reference ${ }^{34)}$ ).

(A) Appearance of perinatal control and E-RAMP2-/- mice. E-RAMP2-/- mice showed severe systemic edema. (B, C) Electron micrographs of aortas from control and E-RAMP2-/- mouse embryos. E-RAMP2-/- endothelial cells showed deformities and were partially detached (arrows). Scale bars $=5 \mu \mathrm{m}$.

\section{Receptor System Used by AM and its Family Peptides}

The main body of the AM receptor is CLR, a 7-transmembrane domain $G$ protein-coupled receptor. CLR associates with one of the three RAMP subtypes, which determines the affinity of CLR for its ligands ${ }^{19,20)}$. CT receptor and CLR interact with multiple ligands from the CT peptide family, the members of which are CT, CGRP, AM, AMY, and intermedin. CT family peptides have diverse and overlapping physiological actions that include decreasing bone resorption (CT), vasodilation (CGRP and AM) and decreased nutrient intake (AMY), to name just three ${ }^{11,35)}$. A new member, intermedin (also called AM2), which also interacts with the CLR-RAMP complex, was recently added to the family ${ }^{36,37)}$. The CT receptor does not require RAMP to bind and respond to CT, but it can associate with RAMPs. This results in a set of receptors that typically have a high affinity for AMY and varied affinity for CGRP ${ }^{11)}$.

RAMP expression is also modulated by various agents in cell culture and in animal models of human disease $^{38)}$. For example, marked changes induced in the cardiovascular and renal systems provide evidence of an important role for dynamic RAMP regulation in those systems. Studies suggest that regulation of RAMPs can modulate the pathophysiology of conditions linked to RAMP-interacting G protein-coupled receptors. For example, human single nucleotide polymorphism (SNP) study described the relationship between CLR and essential hypertension ${ }^{39)}$. Another human study revealed a relationship between RAMP1 SNPs and the incidence of cerebral infarction ${ }^{40)}$ and the mutation of the human RAMP3 gene has also been reported $^{41)}$.

\section{Targeting Genes in the Endothelial AM-RAMP2 System in Mice}

Genetically engineered knockout mice have proven to be a powerful tool with used to identify and manipulate various mechanisms and pathways and have the potential to shed light on novel targets for therapy. We showed that RAMP2-/- mice have a lethal phenotype similar to that of AM-/- mice, suggesting that the AM-RAMP2 system is specifically involved in vascular development ${ }^{21)}$. To directly clarify the physiological functions of the vascular AM-RAMP2 system, we used the Cre-loxP system to generate vascular endothelial cell-specific AM and RAMP2 knockout mouse lines, including vascular endothelial cell-specific RAMP2-/(E-RAMP2-/-) mice, drug-inducible E-RAMP2-/(DI-E-RAMP2-/-) mice, and vascular endothelial cellspecific AM-/- (E-AM-/-) mice, as well as aged conventional RAMP2 heterozygous knockout (RAMP2+/-) mice $^{34)}$. Using these mice, we were able to determine both the acute and chronic effects of RAMP2 deletion and to demonstrate the contribution made by the AM-RAMP2 system to the maintenance of vascular integrity and organ homeostasis.

Whereas conventional RAMP2-/- embryos die mid-gestation (around $14.5 \mathrm{dpc})^{21,42)}$, E-RAMP2-/embryos survive until later in development, though 
A

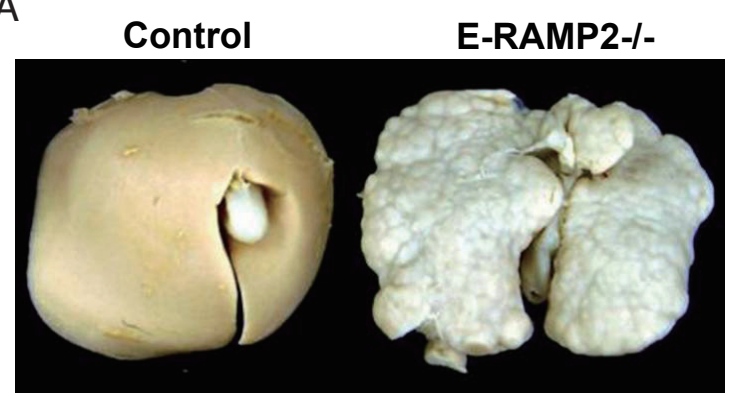

B

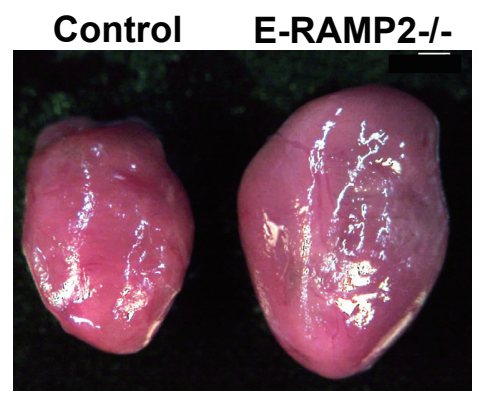

C

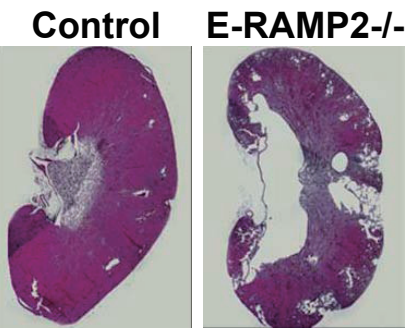

D

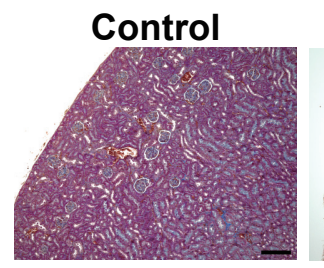

E-RAMP2-/-

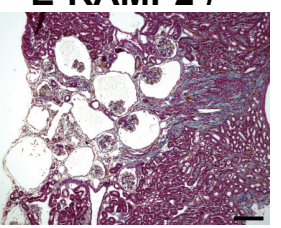

E

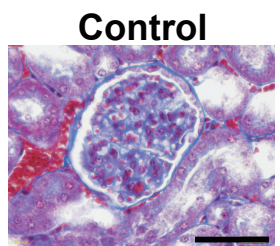

E-RAMP2-/-

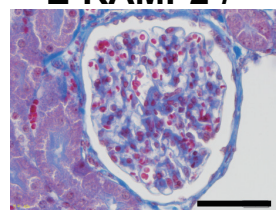

Fig. 2. E-RAMP2-/- mice show progressive organ damage (cited from reference ${ }^{34)}$ ).

(A) Livers showed cirrhosis-like changes in 6-month-old E-RAMP2-/- mice.

(B) Cardiac enlargement was seen in 6-month-old E-RAMP2-/- mice.

(C-E) Histological abnormalities in kidneys from E-RAMP2-/- mice. (C) Section of whole E-RAMP2-/- kidney showing an enlarged renal pelvis. (D) Section of renal cortex from an E-RAMP2-/- kidney showing polycystic changes. Scale bars $=100 \mu \mathrm{m}$. (E) Enlargement of the glomerular area in an E-RAMP2-/- kidney. Scale bars $=50 \mu \mathrm{m}$.

most die during the perinatal period. Perinatal stage E-RAMP2-/- mice exhibit systemic edema (Fig. 1A) as well as vascular abnormalities, including the malformation of aortic endothelial cells and partial detachment of endothelial cells from the basement membrane (Fig. 1B, C). In E-RAMP2-/- embryos, the lesion is limited in the endothelial cells, which likely accounts for their longer survival. Nonetheless, most E-RAMP2-/- mice die because of edema, reflecting the endothelial abnormality and resultant vascular leakage. Clearly, endogenous RAMP2 is essential for endothelial cell viability and vascular integrity. In contrast to E-RAMP2-/- neonates, E-AM-/- neonates appear healthy and present no overtly pathophysiological phenotypes ${ }^{34)}$. This is likely because AM is also secreted from cells other than endothelial cells, and circulating and/or paracrine AM from these other sources would compensate for the endothelial AM deficiency during development.

Among the 5\% of E-RAMP2-/- mice that survive until adulthood, RAMP2 expression in aortic endothelial cells is $20 \%$ of that in the littermate con- trols. Within the surviving E-RAMP2-/- adults, the aortic smooth muscle layers are disarrayed, and the endothelial cells are detached from the basement membrane and are severely deformed. These phenomena suggest congenital endothelial cell abnormalities induce a secondary postnatal disorder affecting other vascular component cells. Furthermore, E-RAMP2-/adults show marked accumulation of inflammatory cells along the blood vessels within major organs, and the chronic vascular damage due to this inflammation likely accelerates vascular senescence ${ }^{5)}$. Although the neonates were normal, E-AM-/- adults showed similar organ damage. Consistent with that idea, 2-year-old RAMP2+/- mice also show inflammatory cell infiltration of their main organs. More interestingly, organ damage developed spontaneously in E-RAMP2-/adults. E-RAMP2-/- adults developed organ damage that included cirrhosis-like changes to the liver (Fig. 2A), cardiac enlargement with fibrosis (Fig. 2B), hydronephrosis, renal polycystic changes, and glomerulosclerosis (Fig. 2C-E). Taken together, these findings suggest endothelial RAMP2 deficiency is a primary 
cause of subsequent vascular inflammation, fibrosis, and chronic organ dysfunction.

We also generated a line of DI-E-RAMP2-/mice, in which we were able to induce endothelial cell-specific RAMP2 gene deletion on demand. DI-ERAMP2-/- mice exhibit marked systemic edema caused by increased vascular permeability. DI-E-RAMP2-/mice did not show edema before the induction of Cre recombinase. However, after the 5 day administration of tamoxifen to induce Cre recombinase, DI-E-RAMP2-/mice showed visible edema from day 5 , mainly in the lower half of the body. The edema gradually extended to the upper half of the body and face, and significant body weight gain compared with control mice was detected from 1 week. When we examined the function of the AM-RAMP2 system during the early stages of retinal angiogenesis ${ }^{43}$, we found that DI-E-RAMP2-/mice retinas showed abnormal vessel development, with delayed vessel progression in the periphery and excessive branching at the vascular front. Actin polymerization in DI-E-RAMP2-/- endothelial cells also appeared in disarray, and there was a loss of actin-bundle formation under the plasma membrane. When we analyzed the activation of Rac1 and RhoA in DI-E-RAMP2-/endothelial cells, we found that levels of the activated form of Rac1 (Rac1-GTP) were significantly reduced, whereas the activated form of RhoA (RhoA-GTP) was increased. These observations suggest the AM-RAMP2 system regulates the Rac1-GTP/RhoA-GTP ratio and thus cortical actin formation, and that a defect in this system disrupts actin formation and endothelial barrier function. With DI-E-RAMP2-/- mice, we were thus able to clarify both the acute and chronic effects of RAMP2 deletion and demonstrate that RAMP2 is essential for endothelial cell viability, vascular integrity, and homeostasis.

Apart from its maintenance of endothelial function, AM also reportedly possesses lymphatic endothelial activity. It was reported that secondary lymphedema induced in the hind-limb skin incision model was more severe in $\mathrm{AM}+/$ - mice, and the edema was prevented when circulating AM levels were restored by the systemic delivery of exogenous peptide ${ }^{44)}$. In addition, drug-induced knockout of CLR has been reported to cause chronic edema and dermal lymphatic insufficiency in adult mice ${ }^{45)}$. These reports suggest that AMCLR signaling is important for the maintenance of normal lymphatic vessels; however, in both AM and CLR knockout mice, all of the signaling mediated by RAMPs (RAMP1-3) are functionally deleted, as either the ligand or receptor is absent.

Because RAMP2 associates with multiple G protein-coupled receptors beyond CLR, it is possible that the vascular phenotypes of RAMP2-/- mice can be attributed to additional signaling pathways, and this notion is further supported by more severe phenotypes of RAMP2+/- mice compared with CLR $+/-$ mice $^{46)}$. To determine which RAMP is fundamentally important for the regulation of lymphatic vessels by AM, it was necessary to separately delete each RAMP isoform. Recently, we reported the functional differentiation of RAMP2 and RAMP3 by using each knockout mice. We found that RAMP3 knockout mice (RAMP3-/-) showed more severe post-operative lymphedema compared with wild-type mice, which was not observed in lymphatic endothelial cell-specific RAMP2-/_47). Moreover, we previously reported that AM-/- mice and RAMP2-/- mice die in utero because of the same defect in vascular development ${ }^{21}$. In contrast, RAMP1 knockout mice and RAMP3 knockout mice were born normally ${ }^{48,49)}$. We also found that aged RAMP2+/- mice spontaneously develop severe organ fibrosis with accelerated vascular senescence in spite of the compensatory upregulation of $\mathrm{AM}^{34)}$. These findings strongly support that RAMP2 is the key determinant of the vascular homeostasis regulated by AM.

\section{Concluding Remarks and Future Perspectives}

AM, originally identified as a vasodilating peptide, is now recognized to be a pleiotropic molecule involved in both circulatory homeostasis and the pathogenesis of cardiovascular diseases. Because of the wide range of its bioactivity, AM has been attracting attention for its potential clinical applications. But like other bioactive endogenous peptides, the clinical applicability of AM has limitations, the most obvious of which is its very short half-life in the blood, which makes its use impractical for the treatment of chronic diseases. However, it is noteworthy that we were able to modulate vascular AM function by manipulating RAMP2. This suggests RAMP2, in particular, to be a therapeutic target through which the vascular function of AM can be manipulated. Because RAMPs are low-molecular-weight proteins, the structural analysis and synthesis of specific agonists or antagonists are much more realistic for RAMPs than for CLR, a 7-transmembrane domain $G$ protein-coupled receptor.

In sum, the vascular AM-RAMP2 system plays critical roles in the regulation of vascular integrity, including the maintenance of vascular structure, regulation of angiogenesis, and vasoprotection against vascular injury. Studies of AM and RAMP2 should bring about novel approaches to the treatment of diseases arising from vascular failure. 


\section{Acknowledgement}

This review is based on a presentation by T.K. who received the Young Investigator Award 2014 from the Japan Atherosclerosis Society at the 46rd Annual Meeting of the Japan Atherosclerosis Society (Tokyo, July 2014).

This work was supported by JSPS KAKENHI Grant Number 25893225.

\section{Conflicts of Interest}

None.

\section{References}

1) Handschin C, Spiegelman BM: The role of exercise and PGC1alpha in inflammation and chronic disease. Nature, 2008; 454: 463-469

2) Medzhitov R: Inflammation 2010: new adventures of an old flame. Cell, 2010; 140: 771-776

3) Cleaver O, Melton DA: Endothelial signaling during development. Nat Med, 2003; 9: 661-668

4) Carmeliet P: Angiogenesis in health and disease. Nat Med, 2003; 9: 653-660

5) Minamino T, Komuro I: Vascular cell senescence: contribution to atherosclerosis. Circ Res, 2007; 100: 15-26

6) Higashi Y, Noma K, Yoshizumi M, Kihara Y: Endothelial function and oxidative stress in cardiovascular diseases. Circ J, 2009; 73: 411-418

7) Mochizuki N: Vascular integrity mediated by vascular endothelial cadherin and regulated by sphingosine 1-phosphate and angiopoietin-1. Circ J, 2009; 73: 2183-2191

8) Dejana E: Endothelial cell-cell junctions: happy together. Nat Rev Mol Cell Biol, 2004; 5: 261-270

9) Kitamura K, Kangawa K, Kawamoto M, Ichiki Y, Nakamura S, Matsuo H, Eto T: Adrenomedullin: a novel hypotensive peptide isolated from human pheochromocytoma. Biochem Biophys Res Commun, 1993; 192: 553-560

10) Abe M, Sata M, Nishimatsu H, Nagata D, Suzuki E, Terauchi Y, Kadowaki T, Minamino N, Kangawa K, Matsuo H, Hirata Y, Nagai R: Adrenomedullin augments collateral development in response to acute ischemia. Biochem Biophys Res Commun, 2003; 306: 10-15

11) Brain SD, Grant AD: Vascular actions of calcitonin generelated peptide and adrenomedullin. Physiol Rev, 2004; 84: 903-934

12) Kato J, Tsuruda T, Kita T, Kitamura K, Eto T: Adrenomedullin: a protective factor for blood vessels. Atheroscler Thromb Vasc Biol, 2005; 25: 2480-2487

13) Nagaya N, Nishikimi T, Yoshihara F, Horio T, Morimoto A, Kangawa K: Cardiac adrenomedullin gene expression and peptide accumulation after acute myocardial infarction in rats. Am J Physiol Regul Integr Comp Physiol, 2000; 278: R1019-1026

14) Shindo T, Kurihara $Y$, Nishimatsu H, Moriyama N, Kakoki M, Wang Y, Imai Y, Ebihara A, Kuwaki T, Ju KH, Minamino N, Kangawa K, Ishikawa T, Fukuda M, Akimoto Y,
Kawakami H, Imai T, Morita H, Yazaki Y, Nagai R, Hirata Y, Kurihara H: Vascular abnormalities and elevated blood pressure in mice lacking adrenomedullin gene. Circulation, 2001; 104: 1964-1971

15) Shindo T, Kurihara H, Maemura K, Kurihara Y, Kuwaki T, Izumida T, Minamino N, Ju KH, Morita H, Oh-hashi Y, Kumada M, Kangawa K, Nagai R, Yazaki Y: Hypotension and resistance to lipopolysaccharide-induced shock in transgenic mice overexpressing adrenomedullin in their vasculature. Circulation, 2000; 101: 2309-2316

16) Nishimatsu $H$, Hirata $Y$, Shindo T, Kurihara H, Kakoki M, Nagata D, Hayakawa H, Satonaka H, Sata M, Tojo A, Suzuki E, Kangawa K, Matsuo H, Kitamura T, Nagai R: Role of endogenous adrenomedullin in the regulation of vascular tone and ischemic renal injury: studies on transgenic/knockout mice of adrenomedullin gene. Circ Res, 2002; 90: 657-663

17) Imai $Y$, Shindo T, Maemura K, Sata M, Saito Y, Kurihara Y, Akishita M, Osuga J, Ishibashi S, Tobe K, Morita H, Oh-hashi Y, Suzuki T, Maekawa H, Kangawa K, Minamino N, Yazaki Y, Nagai R, Kurihara H: Resistance to neointimal hyperplasia and fatty streak formation in mice with adrenomedullin overexpression. Arterioscler Thromb Vasc Biol, 2002; 22: 1310-1315

18) Maki T, Ihara M, Fujita $Y$, Nambu T, Miyashita K, Yamada M, Washida $K$, Nishio $K$, Ito $H$, Harada $H$, Yokoi $H$, Arai H, Itoh H, Nakao K, Takahashi R, Tomimoto H: Angiogenic and vasoprotective effects of adrenomedullin on prevention of cognitive decline after chronic cerebral hypoperfusion in mice. Stroke, 2011; 42: 1122-1128

19) McLatchie LM, Fraser NJ, Main MJ, Wise A, Brown J, Thompson N, Solari R, Lee MG, Foord SM: RAMPs regulate the transport and ligand specificity of the calcitoninreceptor-like receptor. Nature, 1998; 393: 333-339

20) Parameswaran N, Spielman WS: RAMPs: The past, present and future. Trends Biochem Sci, 2006; 31: 631-638

21) Ichikawa-Shindo $Y$, Sakurai T, Kamiyoshi A, Kawate H, Iinuma N, Yoshizawa T, Koyama T, Fukuchi J, Iimuro S, Moriyama N, Kawakami H, Murata T, Kangawa K, Nagai $\mathrm{R}$, Shindo T: The GPCR modulator protein RAMP2 is essential for angiogenesis and vascular integrity. J Clin Invest, 2008; 118: 29-39

22) Tam CW, Husmann K, Clark NC, Clark JE, Lazar Z, Ittner LM, Gotz J, Douglas G, Grant AD, Sugden D, Poston L, Poston R, McFadzean I, Marber MS, Fischer JA, Born W, Brain SD: Enhanced vascular responses to adrenomedullin in mice overexpressing receptor-activitymodifying protein 2 . Circ Res, 2006; 98: 262-270

23) Nishikimi T, Matsuoka H: Cardiac adrenomedullin: its role in cardiac hypertrophy and heart failure. Curr Med Chem Cardiovasc Hematol Agents, 2005; 3: 231-242

24) Shimosawa T, Ogihara T, Matsui $H$, Asano T, Ando K, Fujita T: Deficiency of adrenomedullin induces insulin resistance by increasing oxidative stress. Hypertension, 2003; 41: 1080-1085

25) Ishimitsu T, Nishikimi T, Saito Y, Kitamura K, Eto T, Kangawa K, Matsuo H, Omae T, Matsuoka H: Plasma levels of adrenomedullin, a newly identified hypotensive peptide, in patients with hypertension and renal failure. J Clin Invest, 1994; 94: 2158-2161 
26) Nishikimi T, Saito $Y$, Kitamura $K$, Ishimitsu T, Eto T, Kangawa K, Matsuo H, Omae T, Matsuoka H: Increased plasma levels of adrenomedullin in patients with heart failure. J Am Coll Cardiol, 1995; 26: 1424-1431

27) Nagaya N, Mori H, Murakami S, Kangawa K, Kitamura S: Adrenomedullin: angiogenesis and gene therapy. Am J Physiol Regul Integr Comp Physiol, 2005; 288: R14321437

28) Iimuro S, Shindo T, Moriyama N, Amaki T, Niu P, Takeda N, Iwata H, Zhang Y, Ebihara A, Nagai R: Angiogenic effects of adrenomedullin in ischemia and tumor growth. Circ Res, 2004; 95: 415-423

29) Kim W, Moon SO, Sung MJ, Kim SH, Lee S, So JN, Park SK: Angiogenic role of adrenomedullin through activation of Akt, mitogen-activated protein kinase, and focal adhesion kinase in endothelial cells. FASEB journal : official publication of the Federation of American Societies for Experimental Biology, 2003; 17: 1937-1939

30) Temmesfeld-Wollbruck B, Hocke AC, Suttorp N, Hippenstiel S: Adrenomedullin and endothelial barrier function. Thromb Haemost, 2007; 98: 944-951

31) Prasain N, Stevens T: The actin cytoskeleton in endothelial cell phenotypes. Microvasc Res, 2009; 77: 53-63

32) Yurugi-Kobayashi $T$, Itoh $H$, Schroeder $T$, Nakano $A$, Narazaki G, Kita F, Yanagi K, Hiraoka-Kanie M, Inoue E, Ara T, Nagasawa T, Just U, Nakao K, Nishikawa S, Yamashita JK: Adrenomedullin/cyclic AMP pathway induces Notch activation and differentiation of arterial endothelial cells from vascular progenitors. Atheroscler Thromb Vasc Biol, 2006; 26: 1977-1984

33) Aslam M, Gunduz D, Schuler D, Li L, Sharifpanah F, Sedding D, Piper HM, Noll T: Intermedin induces loss of coronary microvascular endothelial barrier via derangement of actin cytoskeleton: role of RhoA and Rac1. Cardiovasc Res, 2011; 92: 276-286

34) Koyama T, Ochoa-Callejero L, Sakurai T, Kamiyoshi A, Ichikawa-Shindo Y, Iinuma N, Arai T, Yoshizawa T, Iesato Y, Lei Y, Uetake R, Okimura A, Yamauchi A, Tanaka M, Igarashi K, Toriyama Y, Kawate H, Adams RH, Kawakami H, Mochizuki N, Martinez A, Shindo T: Vascular endothelial adrenomedullin-RAMP2 system is essential for vascular integrity and organ homeostasis. Circulation, 2013; 127: 842-853

35) Kuwasako K, Cao YN, Nagoshi Y, Kitamura K, Eto T: Adrenomedullin receptors: pharmacological features and possible pathophysiological roles. Peptides, 2004; 25: 20032012

36) Takei $Y$, Inoue $K$, Ogoshi $M$, Kawahara $T$, Bannai $H$, Miyano S: Identification of novel adrenomedullin in mammals: a potent cardiovascular and renal regulator. FEBS Lett, 2004; 556: 53-58

37) Roh J, Chang CL, Bhalla A, Klein C, Hsu SY: Intermedin is a calcitonin/calcitonin gene-related peptide family peptide acting through the calcitonin receptor-like receptor/ receptor activity-modifying protein receptor complexes. J Biol Chem, 2004; 279: 7264-7274

38) Udawela M, Hay DL, Sexton PM: The receptor activity modifying protein family of $\mathrm{G}$ protein coupled receptor accessory proteins. Semin Cell Dev Biol, 2004; 15: 299308

39) Sano M, Kuroi N, Nakayama T, Sato N, Izumi Y, Soma M, Kokubun S: Association study of calcitonin-receptorlike receptor gene in essential hypertension. Am J Hypertens, 2005; 18: 403-408

40) Nakazato T, Nakayama T, Naganuma T, Sato N, Fu Z, Wang Z, Soma M, Sugama K, Hinohara S, Doba N: Haplotype-based case-control study of receptor (calcitonin) activity-modifying protein-1 gene in cerebral infarction. J Hum Hypertens, 2010; 24: 351-358

41) Bailey RJ, Bradley JW, Poyner DR, Rathbone DL, Hay DL: Functional characterization of two human receptor activity-modifying protein 3 variants. Peptides, 2010;31: 579-584

42) Fritz-Six KL, Dunworth WP, Li M, Caron KM: Adrenomedullin signaling is necessary for murine lymphatic vascular development. J Clin Invest, 2008; 118: 40-50

43) Iesato Y, Toriyama Y, Sakurai T, Kamiyoshi A, IchikawaShindo Y, Kawate H, Yoshizawa T, Koyama T, Uetake R, Yang L, Yamauchi A, Tanaka M, Igarashi K, Murata T, Shindo T: Adrenomedullin-RAMP2 system is crucially involved in retinal angiogenesis. Am J Pathol, 2013; 182: 2380-2390

44) Nikitenko LL, Shimosawa T, Henderson S, Makinen T, Shimosawa H, Qureshi U, Pedley RB, Rees MC, Fujita T, Boshoff C: Adrenomedullin haploinsufficiency predisposes to secondary lymphedema. J Invest Dermatol, 2013; 133: $1768-1776$

45) Hoopes SL, Willcockson HH, Caron KM: Characteristics of multi-organ lymphangiectasia resulting from temporal deletion of calcitonin receptor-like receptor in adult mice. PLoS One, 2012; 7: e45261

46) Kadmiel M, Fritz-Six K, Pacharne S, Richards GO, Li M, Skerry TM, Caron KM: Research resource: Haploinsufficiency of receptor activity-modifying protein-2 (RAMP2) causes reduced fertility, hyperprolactinemia, skeletal abnormalities, and endocrine dysfunction in mice. Mol Endocrinol, 2011; 25: 1244-1253

47) Yamauchi A, Sakurai T, Kamiyoshi A, Ichikawa-Shindo Y, Kawate H, Igarashi K, Toriyama Y, Tanaka M, Liu T, Xian X, Imai A, Zhai L, Owa S, Arai T, Shindo T: Functional differentiation of RAMP2 and RAMP3 in their regulation of the vascular system. J Mol Cell Cardiol, 2014; 77: 73-85

48) Dackor R, Fritz-Six K, Smithies O, Caron K: Receptor activity-modifying proteins 2 and 3 have distinct physiological functions from embryogenesis to old age. J Biol Chem, 2007; 282: 18094-18099

49) Tsujikawa K, Yayama K, Hayashi T, Matsushita H, Yamaguchi T, Shigeno T, Ogitani Y, Hirayama M, Kato T, Fukada S, Takatori S, Kawasaki H, Okamoto H, Ikawa M, Okabe M, Yamamoto H: Hypertension and dysregulated proinflammatory cytokine production in receptor activity-modifying protein 1-deficient mice. Proc Natl Acad Sci U S A, 2007; 104: 16702-16707 